\title{
ORAL HEALTH BELIEFS, KNOWLEDGE, AND BEHAVIORAL ATTITUDES OF EGYPTIAN MOTHERS RESIDENT IN GIZA CITY TOWARDS EARLY CHILDHOOD CARIES
}

\author{
Naglaa Ibrahim Ezzeldin Soliman*
}

\begin{abstract}
Objective: The objective of this study is the evaluation of the oral health beliefs, knowledge and behavior related to the early childhood caries and the barriers may be facing mothers to obtain proper health care in a sample representing Egyptian mothers living in Giza city.

Methods: A cross sectional questionnaire based study was carried out including 440 mothers who do have a child with age of 6 years or younger. This questionnaire was designed to evaluate the participant characteristics and to assess their oral health beliefs and knowledge score (22 questions) and oral health behavior score (10 questions), the scores were calculated by summing the correctly answered questions. And also to determine the possible barriers to obtain proper oral health care (7 questions).
\end{abstract}

Results: The analysis of the data did reveal that $48.4 \%$ of the participants answered 16 to 22 questions correctly in the oral health beliefs and knowledge sector, while $49.3 \%$ of the participant answered 4-6 questions correctly in the oral health behavior sector, while the answers in the barrier section did reveal that $94.3 \%$ of the participants were facing 3 to 7 barriers to obtain oral health care. The oral health beliefs and knowledge showed a statistically significant positive correlation with oral health behavior and the barriers to obtain proper oral health care $(P$ value $=0.000)$.

Conclusion: Although the participants were confronted with some barriers to reach proper oral health care, they revealed an internal proper oral health knowledge associated with accepted oral health behavior.

KEY WORDS: questionnaire, preschool children, primary teeth, oral health

\section{INTRODUCTION}

Early childhood caries (ECC) is a one of the most chronic and prevalent disease affecting the childhood especially in developing countries ${ }^{(1,2)}$. American Academy of Pediatric Dentistry defined the early childhood caries as the occurrence of one or more decayed, missing (due to caries) or filled

* Lecturer of Pediatric Dentistry Department, Faculty of Dentistry, October University of Modern Sciences and Arts, Cairo, Egypt. 
tooth in the primary dentition of the child younger than six year ${ }^{(3)}$.

Prevalence of ECC varies worldwide; in developed countries it ranges from 1 to $12 \%{ }^{(4)}$ compared to the developing countries were the range is between $36 \%$ to $85 \%{ }^{(5)}$.

Giza city is a governorate of greater Cairo, the capital of Egypt, according to the statistical year book 2018 of the Egyptian central agency for public mobilization and statistics; $9.1 \%$ of Egypt population is living in Giza city, and $14.2 \%$ of Giza population is preschool children younger than five years old ${ }^{(6)}$.

In Egypt, prevalence of dental caries did significantly decrease in school children but the incident of dental caries is high in preschool children ${ }^{(7)}$, several studies were conducted to study the prevalence of ECC in Cairo; a study conducted at 2011 revealed that high prevalence of ECC among a group of Egyptian preschool children, the range was $60.4 \%$ with the mean dmf value is $3.3^{(8)}$. Another study was conducted in Cairo during 2014 revealed that $50.3 \%$ of the examined children had dental caries ${ }^{(9)}$.

The etiology of ECC is complex and classified as a biological etiology, including a suitable host, nursing habit, feeding at night, sweetened beverages and other fermentable carbohydrates, also microorganism plays an important role in dental caries especially mutans steptococcus. In developing counties ECC also associated to neglected oral hygiene, social factors as low parental education and low socioeconomic level ${ }^{(10-12)}$.

According to the literatures, the ECC is great among children in large families, moreover the young age of mother, low educational level and insufficient knowledge toward the oral health care ${ }^{(13-15)}$. In young age, child oral health is strongly related to the parental knowledge and attitude toward the oral health care, especially the mother; as the mother is considered the role model of the behavior for her child. Therefore, mother may play a major role in shaping the oral health care, knowledge and attitude of the child ${ }^{(16,17)}$.

ECC have an impact on the child, family and the community, which leads to pain, infection, debilitation in the oral function, also it may affect the child psychologically which have an impact on child quality of life ${ }^{(11,18)}$. In addition, the dental caries is expensive to treat and posing an economic burden on the family ${ }^{(19)}$.

The prevention of the disease is better than treatment, and focusing on the parents to improve the oral health status of their children is an essential parameter ${ }^{(17)}$. In Egypt, the oral health education programs are rarely applied, so the collection of specific data about knowledge, beliefs, behavior, and barriers that may face the mother towards ECC are essential to establish preventive oral health programs ${ }^{(2,10)}$. Therefore, the purpose of this study is the evaluation of the oral health beliefs, knowledge and behavior related to the early childhood caries and the barriers may be facing mothers to obtain proper health care in a sample representing Egyptian mothers living in Giza city.

\section{MATERIALS AND METHODS}

A cross sectional questionnaire based study was carried out in Giza city, a one of the governorate of greater Cairo, the capital of Egypt. The study participants were selected from the pediatric dentistry clinic of October University for Modern Sciences and Arts (MSA). The eligibility criteria was; a mother aged between 18 to 50 years, have a child with age of 6 years or younger and approved to participate in the study after signing the informed consent. The sample was recruited by using consecutive participant sampling; all mothers met the inclusion criteria at the period between October and December 2018 were selected. At the end of the study 440 completely answered questionnaire 
were collected and 40 incompletely answered were excluded.

The protocol was approved by the Research Ethical Committee of Faculty of Dentistry, MSA University. The objectives and nature of the study were explained to the participants, and then the informed consent documents were filled by the participants following Declaration of Helsinki Ethical Principles for Medical Research Involving Human Subject.

The questionnaire in oral health behavior was a modification from a survey done by the National Institute of Dental and Craniofacial Research (NIDCR) Early Childhood Caries Collaborating Centers (EC4) and from Heaton et al., the survey is the application of several health behaviour theories explaining the probability that individuals will participate (or do not participate) in positive oral health behaviors ${ }^{(20,21)}$.

The questionnaire was written in English and translated to simple Arabic language, including four sections; first section representing the characteristics of the study participants; as maternal age, education, employment status of the mother, oral health status of the mother and her child and the number of children in the family. Second section consisted of 22 questions evaluating oral health beliefs and knowledge, third section consisted of 10 questions evaluating oral health behavior and the last section consisted of 7 questions reporting the possible barriers to obtain proper oral health care. The questions were closed ended provided by the multiple answers; any explanations or comments about the questions have been managed by the investigator.

\section{Data analysis}

Descriptive analysis charts were based on both participant characteristics and response to the questionnaire items. The scoring were calculated by summing the correctly answered questions for oral health beliefs and knowledge (score range between 0-22) and behavior (score range between 0-10), the correct answers were determined according to a widely accepted oral health care recommendations for pediatric populations and the American Academy of Pediatric Dentistry recommendations ${ }^{(3,21)}$. An additional scoring was created for the barriers to obtain proper oral health care (score range between 0-7), the barrier based on the higher risk response, as an absence of medical insurance and the length of dental treatment.

Data were statistically described in terms of mean \pm standard deviation $( \pm S D)$, and range, or frequencies (number of cases) and percentages when appropriate. Correlation between various variables was done using Spearman rank correlation equation. $P$ values less than 0.05 was considered statistically significant. All statistical calculations were done using computer program IBM SPSS (Statistical Package for the Social Science; IBM Corp, Armonk, NY, USA) release 22 for Microsoft Windows.

\section{RESULTS}

A proper sample of 440 mothers completed the study questionnaire, living in Giza city, Egypt. Table 1 represents study participant characteristics, $55.2 \%$ of mother's age range was between 26 and 34 years, $56.6 \%$ had high school or college education, while only $20.7 \%$ were employed. $46.8 \%$ of mothers reported their oral health status as excellent or good and $51.4 \%$ reported their child oral health status as excellent or good. $59.1 \%$ had more than 2 children in a family.

The oral health beliefs and knowledge score showed a statistically significant positive correlation with oral health behavior and the barriers to obtain proper oral health care scores $(p$ value $=0.000$ ) (table 2).

Participant's response toward oral health beliefs and knowledge represented in table $3,48.4 \%$ of the participants were reported an average 16 to 22 score, participants showed a highest level of oral 
health knowledge to the effect of drinking soda, eating sweets and sugary food and brushing the mother to her teeth $(90.9 \%, 91.4 \%$ and $95.5 \%)$ respectively (table 3 , item 16, 17 and 20), while they showed lowest oral health knowledge about the time of child first dental checkup and number of fluoride varnish application per year $(23.9 \%$ and $16.4 \%$ ) respectively (table 3 , item 5 and 9 ).

Questions related to oral health behavior were showed in table $4,49.3 \%$ of the participants were reported an average 4 to 6 scores, mothers answered that they do help their children in teeth brushing and brushing their own teeth with highest frequency $(68.6 \%$ and $64.1 \%$ ) respectively (table 4 , item 3 and 10 ), in another hand, they reported low frequency to the behavior related to the times of eating or drinking sweets and sugary foods and fluoride varnish application on the child teeth during the past year $(31.8 \%, 32 \%$ and 8.6$)$ respectively (table 4, item 4, 5 and 8).

The barriers to obtain proper oral health care were reported in table 5, where $94.3 \%$ facing (3-7) barrier, absence of medical insurance for mother and child, time spent in dental visit and the method of travelling to dentist were reported as a barriers facing the majority of the sample $(80.7 \%, 86.6$ and $80 \%$ and $87.5 \%$ ) respectively (table 5 , item $1,2,4$ and 7).

The correlation between the participant characteristics and oral health knowledge and behavior scores were represented in table 6 , there is a statistically significant positive correlations between maternal age and education and oral health beliefs and knowledge score ( $p$ value $=0.027$ and 0.000 ) respectively, while there is a negative correlation between employment status of the mother and oral health beliefs and knowledge, and oral health behavior scores ( $p$ value $=0.001$ and $0.038)$ respectively.

In addition, There is statistically significant positive correlation between child and mother oral health status, and barriers to obtain proper oral health care score $(p$ value $=0.000$ and 0.013$)$ respectively, and a statistically significant positive correlation between child oral health status and oral health behavior score $(p$ value $=0.005)($ table 6 and 7).

TABLE (1) Characteristics of the study participants

\begin{tabular}{|c|c|c|}
\hline & Frequency & Percent $\%$ \\
\hline Maternal age: & & \\
\hline $18-25$ & 82 & $18.6 \%$ \\
\hline $26-34$ & 234 & $55.2 \%$ \\
\hline $35-50$ & 115 & $26.1 \%$ \\
\hline Education: & & \\
\hline Below the high school & 191 & $43.4 \%$ \\
\hline High school or collage & 249 & $56.6 \%$ \\
\hline Employment: & & \\
\hline Employed & 91 & $20.7 \%$ \\
\hline Unemployed & 349 & $79.3 \%$ \\
\hline Mother oral health status: & & \\
\hline Excellent/good & 206 & $46.8 \%$ \\
\hline Fair/poor & 234 & $53.2 \%$ \\
\hline Child oral health status: & & \\
\hline Excellent/good & 226 & $51.4 \%$ \\
\hline Fair/poor & 214 & $48.6 \%$ \\
\hline $\begin{array}{l}\text { Number of children in the } \\
\text { family: }\end{array}$ & & \\
\hline 1 or 2 & 180 & $40.9 \%$ \\
\hline More than 2 & 260 & $59.1 \%$ \\
\hline
\end{tabular}

TABLE (2) Correlation between oral health beliefs and knowledge, oral health behavior and barriers to obtain oral health care scores.

\begin{tabular}{|c|c|c|c|c|}
\hline & & & $\begin{array}{c}\text { Behavior } \\
\text { score }\end{array}$ & $\begin{array}{c}\text { Barriers } \\
\text { score }\end{array}$ \\
\hline \multirow{6}{*}{ 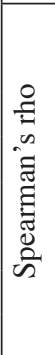 } & \multirow{3}{*}{$\begin{array}{c}\text { Beliefs \& } \\
\text { knowledge } \\
\text { score (total } \\
\text { 22) }\end{array}$} & $\begin{array}{l}\text { Correlation } \\
\text { Coefficient }\end{array}$ & 0.171 & 0.197 \\
\hline & & $P$ value & $0.000^{*}$ & $0.000^{*}$ \\
\hline & & $\mathrm{N}$ & 440 & 440 \\
\hline & \multirow{3}{*}{$\begin{array}{c}\text { Behavior } \\
\text { score (total } \\
10)\end{array}$} & $\begin{array}{l}\text { Correlation } \\
\text { Coefficient }\end{array}$ & & -0.031 \\
\hline & & $P$ value & & 0.511 \\
\hline & & $\mathrm{N}$ & & 440 \\
\hline
\end{tabular}

*: Significant at $P \leq 0.05$ 
TABLE (3) Participants response toward oral health beliefs and knowledge

\begin{tabular}{|c|c|c|}
\hline & $\begin{array}{l}\mathrm{N}= \\
440\end{array}$ & $\begin{array}{c}\text { Percent } \\
\%\end{array}$ \\
\hline $\begin{array}{l}\text { 1- Cleaning of the pacifier in your own mouth in case it has fallen down and giving to child spreads } \\
\text { cavity germs. Yes }{ }^{\dagger}\end{array}$ & 366 & $83.2 \%$ \\
\hline 2- Using same spoon to taste the food and feed the child spreads cavity germs. Yes ${ }^{\dagger}$ & 325 & $73.9 \%$ \\
\hline 3- Sharing a child toothbrush with his family or friends spreads cavity germs. Yes ${ }^{\dagger}$ & 351 & $79.8 \%$ \\
\hline 4- Kissing a baby on his cheek spreads cavity germs. $\mathrm{No}^{\dagger}$ & 225 & $51.1 \%$ \\
\hline $\begin{array}{l}\text { 5- At what age should a child have his/her first dental checkup by a dentist? Less than } 1 \text { year or } 1 \\
\text { year old }{ }^{\dagger}\end{array}$ & 105 & $23.9 \%$ \\
\hline $\begin{array}{l}\text { 6- On average, how many times a year should a child see a dentist for dental care? Two times or more } \\
\text { times }^{\dagger}\end{array}$ & 313 & $71.1 \%$ \\
\hline 7- How many times a day should a child brush his/her teeth? Two times or more times ${ }^{\dagger}$ & 381 & $86.6 \%$ \\
\hline $\begin{array}{l}\text { 8- If a child has no teeth, how many times per day should a child's gums be wiped? Two times or } \\
\text { more times }\end{array}$ & 206 & $46.8 \%$ \\
\hline $\begin{array}{l}\text { 9- How many times a year should fluoride varnish be applied to a child's teeth? Two times or more } \\
\text { times }^{\dagger}\end{array}$ & 72 & $16.4 \%$ \\
\hline 10- Cavities are caused by mouth germs. True ${ }^{\dagger}$ & 369 & $83.9 \%$ \\
\hline 11- It is better to use fluoridated toothpaste when brushing a child's teeth. True ${ }^{\dagger}$ & 318 & $72.3 \%$ \\
\hline $\begin{array}{l}\text { 12- Putting the child in the bed with a Sippy cup or bottle with anything other than water can hurt a } \\
\text { child's teeth. True }\end{array}$ & 275 & $62.5 \%$ \\
\hline 13-Baby teeth are not important because they do not stay in child's mouth very long. False ${ }^{\dagger}$ & 249 & $56.6 \%$ \\
\hline 14- There is no need to visit a dentist unless the child has a problem with his/her teeth. False ${ }^{\dagger}$ & 262 & $59.5 \%$ \\
\hline 15- Eating something after teeth brushing and before going to bed affects child's teeth. Bad $^{\dagger}$ & 352 & $80.0 \%$ \\
\hline 16- Drinking soda affects child's teeth. Bad $\dagger$ & 400 & $90.9 \%$ \\
\hline 17- Eating sweet or sugary foods affects a child's teeth. $\mathrm{Bad}^{\dagger}$ & 402 & $91.4 \%$ \\
\hline 18- Drinking milk from a Sippy cup affects child's teeth. Bad ${ }^{\dagger}$ & 252 & $57.3 \%$ \\
\hline 19- Applying fluoride varnish on child's teeth affects child's teeth. Good ${ }^{\dagger}$ & 286 & $65.0 \%$ \\
\hline 20- Brushing your own teeth daily affects child's teeth. Good $\dagger$ & 420 & $95.5 \%$ \\
\hline 21- Brushing child's teeth or wiping gums daily (if child has no teeth) affects child's teeth. Good & 305 & $69.3 \%$ \\
\hline 22- Checking your child's teeth monthly for any changes or spots. Good ${ }^{\dagger}$ & 395 & $89.8 \%$ \\
\hline \multicolumn{3}{|l|}{ Total score: } \\
\hline $0-5$ & 0 & $0.0 \%$ \\
\hline $6-10$ & 36 & $8.2 \%$ \\
\hline $11-15$ & 191 & $43.4 \%$ \\
\hline $16-22$ & 213 & $48.4 \%$ \\
\hline
\end{tabular}

Number and percentage reported correct responses only 
TABLE (4) Participants response toward oral health behavior

\begin{tabular}{|c|c|c|}
\hline & $\mathrm{N}=440$ & Percent $\%$ \\
\hline 1- During the past year, did your child visit a dentist for a routine checkup or cleaning? Yes ${ }^{\dagger}$ & 160 & $36.4 \%$ \\
\hline $\begin{array}{l}\text { 2- How often are your child's gums and teeth wiped or brushed per day? } \\
\text { Two times or more times }\end{array}$ & 224 & $50.9 \%$ \\
\hline 3- Do you or another adult help your child during teeth brushing? Yes ${ }^{\dagger}$ & 302 & $68.6 \%$ \\
\hline 4- How many times does your child eat sweet or sugary foods? Rarely or at least once per week ${ }^{\dagger}$ & 140 & $31.8 \%$ \\
\hline $\begin{array}{l}\text { 5- How many times does your child drink sweet or sugary drinks? Rarely or at least once per } \\
\text { week }^{\dagger}\end{array}$ & 141 & $32.0 \%$ \\
\hline $\begin{array}{l}\text { 6- In past week, how many times did your child eat or drink something other than water after } \\
\text { brushing teeth/wiping gums and before going to sleep? } 0 \text { time }^{\dagger}\end{array}$ & 145 & $33.0 \%$ \\
\hline $\begin{array}{l}\text { 7- How many times does your child put anything in his/her mouth that has been in someone else's } \\
\text { mouth? } 0 \text { time }\end{array}$ & 275 & $62.5 \%$ \\
\hline 8- During the past year, did your child apply fluoride varnish on his/her teeth? Yes ${ }^{\dagger}$ & 38 & $8.6 \%$ \\
\hline $\begin{array}{l}\text { 9- If yes, how many times during the past year has your child had fluoride varnish applied? Two } \\
\text { times or more times }\end{array}$ & 23 & $5.2 \%$ \\
\hline 10- How many times do you brush your own teeth per day? Two times or more times ${ }^{\dagger}$ & 282 & $64.1 \%$ \\
\hline Total score: & & \\
\hline $0-3$ & 187 & $42.5 \%$ \\
\hline 4-6 & 217 & $49.3 \%$ \\
\hline $7-10$ & 36 & $8.2 \%$ \\
\hline
\end{tabular}

Number and percentage reported correct responses only

\section{$\dagger$ Indicates correct answers}

TABLE (5) Participants response toward barriers to obtain proper oral health care

\begin{tabular}{|c|c|c|}
\hline & $\mathrm{N}=440$ & Percent $\%$ \\
\hline 1- Do you now have a dental insurance that pays for all or part of your child's dental care? Yes & 71 & $16.1 \%$ \\
\hline No $\dagger$ & 355 & $80.7 \%$ \\
\hline No response & 14 & $3.2 \%$ \\
\hline 2- Do you now have a dental insurance that pays for all or part of your dental care? Yes & 53 & $12.0 \%$ \\
\hline $\mathrm{No}^{\dagger}$ & 381 & $86.6 \%$ \\
\hline No response & 6 & $1.4 \%$ \\
\hline $\begin{array}{l}\text { 3- During the past year, was there an urgent and immediate need for a dental care but failed to get } \\
\text { it in time? Yes }\end{array}$ & 154 & $35.0 \%$ \\
\hline No & 278 & $63.2 \%$ \\
\hline No response & 8 & $1.8 \%$ \\
\hline 4- What is the average time taken in a dental visit from the beginning till the end? & & \\
\hline 30 minutes or less & 59 & $13.4 \%$ \\
\hline An hour or more than an hour ${ }^{\dagger}$ & 352 & $80.0 \%$ \\
\hline No response & 29 & $6.6 \%$ \\
\hline
\end{tabular}




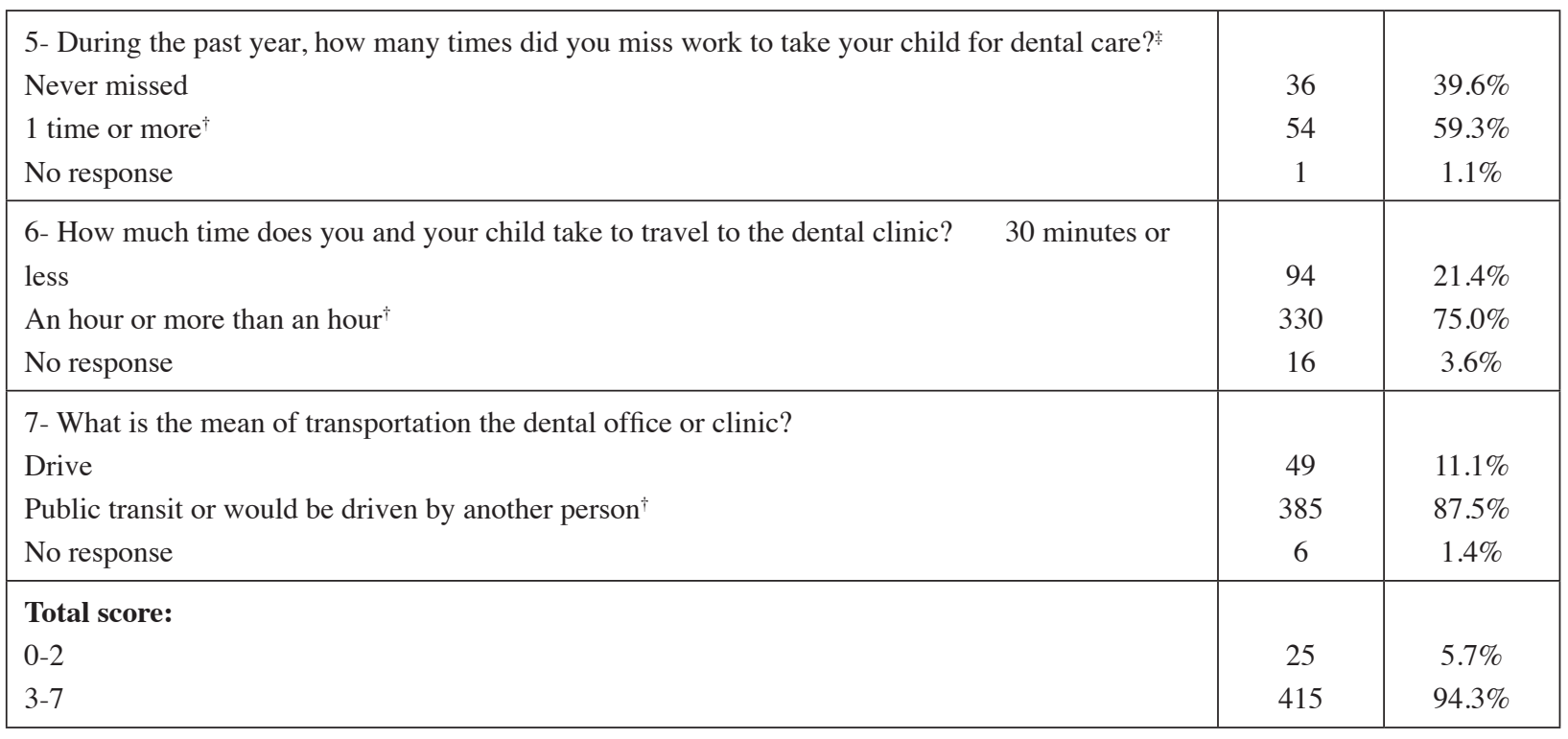

\section{: Indicate response as a barrier}

f: Total employed mothers $(n=91)$ mother

TABLE (6) Correlation between participant characteristics and oral health beliefs and knowledge and oral health behavior scores

\begin{tabular}{|c|c|c|c|c|}
\hline & & & Beliefs \& knowledge score & Behavior score \\
\hline \multirow{15}{*}{$\begin{array}{l}\text { Spearman's } \\
\text { rho }\end{array}$} & \multirow[t]{3}{*}{ Maternal age } & Correlation Coefficient & 0.106 & -0.026 \\
\hline & & $P$ value & $0.027^{*}$ & 0.589 \\
\hline & & $\mathrm{N}$ & 440 & 440 \\
\hline & \multirow[t]{3}{*}{ Education } & Correlation Coefficient & 0.222 & 0.050 \\
\hline & & $P$ p value & $0.000^{*}$ & 0.291 \\
\hline & & $\mathrm{N}$ & 440 & 440 \\
\hline & \multirow[t]{3}{*}{ Employment status } & Correlation Coefficient & -0.156 & -0.099 \\
\hline & & $P$ value & $0.001^{*}$ & $0.038^{*}$ \\
\hline & & $\mathrm{N}$ & 440 & 440 \\
\hline & \multirow{3}{*}{$\begin{array}{l}\text { Number of children in } \\
\text { a family }\end{array}$} & Correlation Coefficient & 0.014 & -0.056 \\
\hline & & $P$ value & 0.764 & 0.244 \\
\hline & & $\mathrm{N}$ & 440 & 440 \\
\hline & \multirow[t]{3}{*}{ Child oral health status } & Correlation Coefficient & -0.050 & -0.134 \\
\hline & & $P$ value & 0.296 & $0.005^{*}$ \\
\hline & & $\mathrm{N}$ & 440 & 440 \\
\hline
\end{tabular}

*: Significant at $P \leq 0.05$ 
TABLE (7) Correlation between child oral health status and mother oral health status and barriers to obtain oral health care score

\begin{tabular}{|l|l|l|l|l|}
\hline \multicolumn{2}{|c|}{} & Mother oral health status & Barriers score \\
\hline Spearman's rho & \multirow{2}{*}{ Child oral health status } & Correlation Coefficient & 0.193 & 0.118 \\
\cline { 3 - 5 } & & $P$ value & $0.000^{*}$ & $0.013^{*}$ \\
\cline { 3 - 5 } & & $\mathrm{N}$ & 440 & 440 \\
\hline
\end{tabular}

*: Significant at $P \leq 0.05$

\section{DISCUSSION}

The outputs of this study indicates that the participants had a proper oral health beliefs and knowledge which is statistically significant positive correlated with the oral health behavior score, this result was consistent with Alya et al.(22) and contradicted by Chala et al. ${ }^{(23)}$, as they found that mothers had low knowledge and behavior, this contradiction may be due to differences in socioeconomic background and educational culture

In spite of this result, the study participants had high level of oral health beliefs and knowledge related to some questions, however they were not able to apply those beliefs in real life actions regarding oral health care behavior, as most of them reported the bad effect of sweet consumption and eating something other than water after teeth brushing and before going to the bed, however the practicing of this knowledge were not reported as well as their beliefs. Those obtained results comply with Abu Hamila, Abduljalil and Abuaffan ${ }^{(10,24)}$. It could be explained as $43.4 \%$ of the participants reported that the primary teeth are not important because they do not stay in child mouth for a long time, this findings is endorsed by the studies of Hamila, Ghhabra and Ghhabra ${ }^{(10,25)}$.

Also, despite $65 \%$ of participants believed in the good effect of fluoride varnish application, there were only $16.4 \%$ who were familiar with the recommended times of fluoride application on the child teeth per year and only $8.6 \%$ who did apply fluoride varnish on the child teeth in the past year. These results were consistent with several studies in developing countries ${ }^{(24-26)}$, it could be explained as the $40.5 \%$ of the participants in this study believed that there is no need to visit the dentist unless the child is facing a problem, also only $36.4 \%$ who did visit the dentist for routine checkup. Therefore it is an essential parameter for establishing effective oral health care programs to educate the parents about the importance of primary teeth and different preventive therapies. Also, the study participants are facing a number of barriers which may be interfering with access not only to the preventive therapy but also to the dental treatment.

Child first dental visit and wiping infant gum are knowledge and behaviors that needs to be improved or applied probably, those results do agree with Chala et al. ${ }^{(23)}$. According to the AAPD the first dental visit should be associated with the eruption of first primary tooth and maximum by age of one year, as it gives the dentist an opportunity to advise parents with oral health care information, in addition wiping a gum and teeth brushing as soon as the first primary tooth erupt help to reduce ECC ${ }^{(3)}$.

94.3\% of the study participants are facing several barriers as absence of the medical insurance, length of the dental visit; time spent travelling to the dental clinic and the method of transportation to the clinic and back.

In addition there is a significant positive correlation between the barriers to obtain oral health 
care score and oral health beliefs and knowledge score, despite of having many barriers reported in this study the participants had proper oral health knowledge, the possible explanation of this result that participants did gain the knowledge from other sources rather than the dentist, as media, books or internet. This was a limitation in this study as the source of information should be reported to allow the determination of the suitable method of distribution of the oral health care information. These results do contradict with other research applied by Heaton et al. in population of American Indian and Alaska Native ${ }^{(21)}$, as this sample reported a high level of knowledge and low number of barriers, this contradictory may be due to different population structure and cultural effect between different countries.

Absence of dental insurance may be attributed to study sample were taken from free and public health care place that does not require any dental insurance, so it may be targeted by people who didn't have insurance, in addition the low economic level of the people targeting this type of free health care units, cannot afford private transportation car, which considered as one of this study limitation as the study was applied in single location that may not reflect all types of population in Giza city. Also increasing the number and distribution of pediatric dentistry clinics in Egypt is essential to reduce the barriers associated with the length of dental visit and time spent for travelling to the clinic.

There was a significant positive correlation between oral health beliefs and knowledge scores with both maternal age and education, those findings can be explained as more than half of the sample aged between 26 to 34 years who may had a high level of education and able to read and use computer for internet search and gaining information related to the oral health care more than the younger, this result is in accordance with Ashkanani and Al-Sane ${ }^{(27)}$, also there were several studies that reported a correlation between educational level and oral health beliefs and knowledge ${ }^{(24,26,28)}$, in addition there is a significant negative correlation between the employment statues and oral health knowledge and behavior scores as most of the study participants were unemployed which gave them time to gain knowledge and applying it to a real effective behavior, those results were consistent with Sogi et al. and Alzaidi et al. ${ }^{(29,30)}$.

Child oral health status was statistically significant negatively correlated to oral health behavior, also it was statistically positively correlated with mother oral health status and barriers to obtain proper oral health, this results contradict Rai and Tiwari (1), the reason of this contradiction that the studies of this systemic review used $\mathrm{dmft}$ index to evaluate the ECC, which may be considered as another limitation in the present study due to mothers bias when reporting the child oral health status.

Finally, Similar studies needs to be conducted in different regions in Egypt and on different socioeconomic diversities, Also dental organizations and the government should work to eliminate the barriers interfering with obtaining oral health care.

\section{REFERENCES}

1. Rai NK, Tiwari T. Parental factors influencing the development of early childhood caries in developing nations: A Systematic Review. Front Public Health. 2018;6:1-8.

2. Wulaerhan J, Abudureyimu A, Bao X, Zhao J. Risk determinants associated with early childhood caries in Uygur children : a preschool-based cross-sectional study. BMC Oral Health. 2014;14:1-8.

3. American Academy of Pediatric Dentistry. Council on clinical affairs. Policy on Early Childhood Caries (ECC): Classifications, Consequences and Preventive Strategies. 2016;(6):60-62.

4. Congiu G, Campus G, Luglie PF. Early Childhood Caries (ECC) prevalence and background factors: A Review. Oral Health Prev Dent. 2014;12(1):71-76.

5. Aljarallah FA, Alghanim HZ, Bin A, Alanazi T, Abdulaziz K, Abulaban RM, et al. Prevalence of early childhood caries. Egypt J Hosp Med. 2018;70:1259-1265. 
6. The Egyptian central agency for public mobilization and statistics, the statistical year book 2018. Available from: http://www.capmas.gov.eg/Pages/staticPages.aspx?page_ $\mathrm{id}=5034 \mathrm{~A}$

7. Farag S, Rashed M, Fouad W. Oral health status of preschool children in El-Suez governorate in relation to dental care given and the influnce of oral health education programe. Egypt Dent J. 2014;60(1):1103-1113.

8. Abou El-Yazeed M, Rashed M, El sayed M, Salah A. Dental caries prevalence among a group of egyptian nurseries children. Life Science J. 2011;8(1):512-519.

9. Abdelfattah A, Rashed M, Eldokky N. Oral health status of preschool children in Greater Cairo in relation to dental care given and the influnce of oral health education programe. Master degree thesis, Faculty of Oral and Dental Medicine, Cairo University. 2014.

10. Abu Hamila NAA. Early childhood caries and certain risk factors in a sample of children. Dentistry. 2013;4(1):1-7.

11. Li Y, Zhang YE, Yang RAN, Zhang Q, Zou J, Kang D. Associations of social and behavioural factors with early childhood caries in Xiamen city in China.Int $\mathrm{J}$ Paediatr Dent. 2011;21:103-111.

12. Prakash P, Subramaniam P, Durgesh BH, Konde S. Prevalence of early childhood caries and associated risk factors in preschool children of urban Bangalore, India : A crosssectional study. Eur J Dent. 2012;6:141-152.

13. Corrêa-faria P, Martins-Júnior P, Vieira-Andrade R, Marques L, Ramos-Jorge M Factors associated with the development of early childhood caries among Brazilian preschoolers. Braz Oral Res. 2013;27(4):356-362.

14. Wellappuli N, Amarasena N. Influence of family structure on dental caries experience of preschool children in Sri Lanka. Caries Res. 2012;46(3):208-212.

15. Niji R, Arita K, Abe Y, Lucas ME, Nishino M, Mitome M. Maternal age at birth and other risk factors in early childhood caries. Pediatr Dent. 2010;32(7):493-498.

16. Adeniyi AA, Ogunbodede EO, Jeboda OS, Folayan MO. Do maternal factors influence the dental health status of Nigerian pre-school children? Int J Paediatr Dent. 2009;19:448-454.

17. Sujlana A, Pannu PK. Family related factors associated with caries prevalence in the primary dentition of five-yearold children. J Indian Soc Pedod Prev Dent. 2015;33(2): 83-87.

18. American Academy of Pediatric Dentistry. Council on clinical affairs. Policy on Model Dental Benefits for In- fants , Children , Adolescents , and Individuals With Special Health Care Needs. 2017;6:110-113.

19. Petersen PE, Bourgeois D, Ogawa H, Estupinan-Day S, Ndiaye C. The global burden of oral diseases and risks to oral health. Bull World Health Organ. 2005;83(9):661669.

20. Early Childhood Caries Collaborating Centers (EC4). 2016 [cited 2016 Aug 8]. Available from: https://oralhealthdisparities.ucsf.edu.

21. Heaton B, Crawford A, Garcia RI, Henshaw M, Riedy CA, Barker JC, et al. Oral health beliefs , knowledge , and behaviors in Northern California American Indian and Alaska Native mothers regarding early childhood caries. J Public Health Dent. 2017;77(4):350-359.

22. Alya N, Abu F, Mamat Z. Parental knowledge and practices on preschool children oral healthcare in Nibong Tebal Penang Malaysia. JOJ Nurse Health Care. 2018; 7(4):1-5.

23. Chala S, Houzmali S, Abouqal R, Abdallaoui F. Knowledge, attitudes and self-reported practices toward children oral health among mother' s attending maternal and child' s units , Salé , Morocco. BMC Public Health. 2018;18(1):1-8.

24. Abduljalil SH, Abuaffan AH. Knowledge and practice of mothers in relation to dental health of preschool children. Adv Genet Eng. 2016;5(2):1-7.

25. Chhabra N, Chhabra A. Parental knowledge, attitudes and cultural beliefs regarding oral health and dental care of preschool children in an Indian population : a quantitative study. Eur Arch Paediatr Dent. 2012;13(2):76-82.

26. Gurunathan D, Moses J, Arunachalam SK. Knowledge, attitude, and practice of mothers regarding oral hygiene of primary school children in Chennai, Tamil Nadu, India. Int J Clin Pediatr Dent. 2018;11(4):338-343.

27. Ashkanani F, Al-Sane M. Knowledge, attitudes and practices of preschool children. Med Princ Pract. 2013;22:167172.

28. Mubeen N, Nisar N. Mother's knowledge, attitude and practices regarding dental caries and oral hygiene among children (age 1 to 5 years) in civil hospital, Karachi. Int J Dent Oral Health. 2015;2(4):1-6.

29. Sogi HPS, Hugar SM, Nalawade TM, Sinha A, Hugar S, Mallikarjuna RM. Knowledge, attitude and practices of oral health care in prevention of early childhood caries among parents of children in Belagavi city : A Questionnaire study. J Family Med Prim Care. 2016;5(2):286-290.

30. Alzaidi SS, Alanazi IA, Mohammed O, Nawas A, Mulla MA. Childhood oral health: maternal knowledge and practice in Tabuk, Saudi Arabia. Egypt J Hosp Med 2018;70(1):1544-1551. 